\title{
Compulsory Educational Policies in Rural China since 1978: A Macro Perspective
}

\author{
Jian LI \\ Assistant Professor, Faculty of Education, \\ Beijing Normal University, Beijing, China \\ jianli2og@bnu.edu.cn
}

\begin{abstract}
Since 1978 China has implemented a series of educational policies for shaping rural compulsory education in order to improve its quality and competitiveness. This short article takes a macro perspective to review the rural compulsory education policies in contemporary China. Specifically, the macro perspective concentrates on examining the historical urbanization process of basic education in rural areas and the four stages of compulsory educational development in these regions. The article suggests that China has made tremendous contributions on closing the rural and urban gaps in recent years, but challenges remain to be solved.
\end{abstract}

\section{Keywords}

compulsory education - rural education - rural schooling - basic education - China

\section{Introduction}

Education is often considered as a fundamental human right worldwide. To fulfill this right, many countries have taken various measures to ensure the universal access to inclusive and equitable quality education and learning, leaving no one behind. Education should focus on the full development of the human personality and promote mutual understanding, tolerance, friendship and peace. The 2030 Education Action Framework of UNESCO involves ensuring the inclusive and fair quality basic education and promoting lifelong 
learning opportunities for all people (Milana et al., 2017). It is essential for China to implement compulsory education to comprehensively develop a modern education system. Implementing the compulsory education policy in contemporary China is also considered as major governmental endeavor to mean the imperative of "Right of Education".

Since 1970s, China has institutionally implemented a series of educational policies for rural compulsory education in order to enhance its educational equality. In this process, rural education has been viewed as the most important part of promoting universal compulsory education in China. China's compulsory education, especially for rural areas is deeply imbedded in the process of the urbanization. There existed tremendous barriers that impeded the full implementation of rural compulsory education in China, such as handling urban-based curricula and rural teacher recruiting, and keeping qualified rural teachers, and the outflow of local residents. This article concentrates on providing a macro perspective on compulsory educational policies in contemporary China (MOE, 2012).

\section{Rural Compulsory Education Policies and the Urbanization Process}

Since the implementation of "the Reform and Opening Up" policy by the Third Plenary Session of the 11th CPC Central Committee of the Chinese Communist Party, Chinese central government launched a series of educational policies to implement and promote compulsory education in rural areas. In the development of the 40 years from 1978 to 2019, the goal of universal compulsory education is adjusted and changed in different contexts. Specifically, "The Rural Household Contract Responsibility System" plays a fundamental role for rural compulsory education through boosting socioeconomic development. Chinese central government implemented several intensive education policies to support rural teachers. After tax system reform, the investment of finance in rural compulsory education was implemented and focused on the "county based" new mechanism, according to the proportion of responsibility. After the 18th National Congress of the Communist Party of China, Chinese central government launched the national "Educational Poverty Alleviation Plan" to increase the enrollment of rural students from rural areas (MOE and the State Council, 2018). In the trend of urbanization, the central government introduced a couple of education policies to alleviate the gap in the disadvantaged groups, such as migrant children and rural left-behind children (Cheng et al., 1999). 
The urbanization process in China is intertwined with the development of rural compulsory education. From a macro perspective, urbanization plays a significant role in the development of the nine-year compulsory education. Specifically, "The National New Type Urbanization Plan (2014-2020 years)" proposed that the urbanization rate of the resident population and household population increased from $42.4 \%$ and $23.1 \%$ in 2012 to about $56 \%$ and $40 \%$ in 2020. The proportion of rural migrant workers' children who receive compulsory education has improved by 99.5\%. In addition, "The Notification of the Comprehensive Pilot Program for Developing New Urbanization in China" has respectively identified 64 provinces, 73 cities and 111 towns as pilot areas at the national level (Wei and Gong, 2019). The characteristics of the urbanization process in China may be captured by some key terms, including the population migration, the industrial evolution, the employment transformation, and the urban and rural integration. The major challenge in the urbanization process is to transfer a large number of the agricultural population to integrate into urban society. The number of small towns is relatively large, and their scales are small accounting for weak services provided. The institutional mechanism of constructing urbanization in China is not as ideal yet, which may hinder the development of urbanization.

\section{The Four Stages of Rural Compulsory Education Policies}

Considered the rationale of the urbanization process, the historical landmarks, and the remarkable influences of rural education development in China, the developmental stages of improving rural compulsory education could be mainly divided into four stages.

\subsection{Stage 1 (1978-2002)}

Chinese central government aims to popularizing the five-years' compulsory education by proposing the "Promulgation of the Compulsory Education Law" in 1986, following the three-level management, putting forward the two main policies by the Ministry of Public Security and the State Education Committee in 1998, implementing the School Link Project in 2000. By a series of education policies, teachers have gradually withdrawn from the historical stage. In 2001, the Chinese Central Office issued the "Preparation of Teachers" to put forward the slogan of "the Balanced Development of Compulsory Education". The education policy on "the withdrawal of the school and the approval of the county government" received a tremendous impact on the advancing rural compulsory education. 


\subsection{Stage $2(2002-2006)$}

In accordance with strengthening the construction of teachers in rural areas, Chinese central government encourage different types of educational organizations, including different types of colleges or universities to provide sufficient volunteers to meet the needs of the qualified teachers in Chinese western regions. Chinese central government proposed the "county-based" compulsory education in 2002. In February 10, 2004, the Ministry of Education introduced the “2003-2007 Year Plan of Education Revitalization Action Plan”, and put forward the reform of teacher education model, which transformed from the "Old Three Types" of middle level teachers, high level teachers and bachelor degreebased teachers into "New Three Types" of high level teachers, degree-based teachers, and graduated degree-based teachers. In the February 6, 2004, Chinese central government launched the "Western Areas of the Country Two Basics Plan (2004-2007)" to accelerate the construction of the rural boarding schools in western rural areas (MOE, 2004).

In addition, it is difficult to implement the two main steps project to put forward the policy of "Two Exemption and One Supplement" and "One Fee System". Especially, in December 25, 2003, the Ministry of Education and other departments proposed the entitled "Modern Distance Education Project in Rural Primary and Middle Schools" pilot work plan. They focused on proposing the school layout structure adjustment through implementing the "compulsory education project" and "rural schools project for the renovation of dilapidated buildings" in order to enhance urban and rural quality educational resources sharing mechanism and improve the quality of rural education (The Communist Party of China Central Committee \& the State Council, 2014). In 2004, Chinese central government proposed the "One Fee" policy for ordinary primary schools and junior middle schools. Rural primary schools and junior middle schools in key counties are included in the policy implementation of "Poverty Alleviation" and development work.

\subsection{Stage $3(2006-2012)$}

In this stage the central government launched a couple of education policies to ensure the investment mechanism for compulsory education since 2006, such as the "Special Position Plan", "The speed of Layout Adjustment (2010-2011)", "Thin Reform Project in 2010". For example, in 2012 the strategic plan of "The Construction Target of Information Learning Environment and Information Support Service System in 2020" was put forward in order to accelerate the development of rural compulsory education in the long term. In 2012, the Ministry of Education promulgated the "Opinions on Further Promoting 
the Balanced Development of Compulsory Education". It is proposed that tuition fee in the compulsory education stage of rural areas should be waived for two years, and the compulsory education in rural areas is fully integrated into the scope of national financial security (MOE, 2012). Along with the "new mechanism", compulsory education in China has become totally free since 2006. In 2010, The "Thin Reform Plan" was implemented to focus on upgrading experimental equipment, school library, multi-media equipment, boarding school facilities. Schools were expanded in counties and towns, which gradually solved the problem of large classes in counties and towns. The free compulsory education is considered as a great historical progress in the development of education system in China (MOE, 2014).

\subsection{Stage 4 (2012-present)}

Since 2012, the Chinese central government has aggressively initiated several key educational policy implementations, such as the implementation of nine years of compulsory education, the construction of rural teachers, the improved investment mechanism of educational funds, the implementation of education and poverty alleviation (MOE, 2012). For example, in 2012, the Third Plenary Session of the 18th CPC Central Committee proposed the "Establishment of the Principal Teacher Exchange Rotation System" to establish an urban-rural teacher exchange platform for supporting rural teachers with living allowance in underdeveloped counties (MOE et al., 2014). The project of "Three Links and Two Platforms" aims to provide targeted poverty alleviation of rural education. Since 2015, the migrant workers' children could enroll through the school entrance examination for compulsory education. In 2017, the18th CPC Central Committee was held to further improve compulsory education in rural areas.

\section{Conclusion: Opportunities and Challenges for Rural Compulsory Education in China}

China has made tremendous contributions on narrowing the rural and urban gap in recent years and the challenges and barriers are still encountered by contemporary China. Since implementing the policy of "Reform and Opening Up" in 1978, the process of Chinese rural education has been accompanied by the urbanization process, which may be characterized as "Starting Poorly, Achieving Fast". The process of the urbanization has brought tremendous opportunities and challenges to current rural education in contemporary China. 


\section{References}

Cheng, K.M., Jin, X.H., \& Gu, X.B. (1999). From training to education: Lifelong learning in China. Comparative Education, 35(2), 119-129.

Milana, M., Holford, J., Hodge, S., Waller, R., \& Webb, S. (2017). Adult education and learning: Endorsing its contribution to the 2030 Agenda. International Journal of Lifelong Education, 36(6), 625-628.

Ministry of Education. (2014, March 21). The implementation of teaching equipment projects in the thin reform plan has achieved remarkable results. Retrieved from http://www.gov.cn/xinwen/2014-03/21/content_2642823.htm.

Ministry of Education. (2012, September 5). Opinions on further promoting the balanced development of compulsory education. Retrieved from http://www.moe.gov .cn/jyb_xwfb/xw_zt/moe_357/jyzt_2016nztzl/ztzl_xyncs/ztzl_xy_zcfg/201701/ t20170117_295047.html.

Ministry of Education. (2004, February 16). Western areas of the country two basics plan (2004-2007). Retrieved from http://www.moe.gov.cn/jyb_sjzl/moe_364/moe _1172/moe_1201/tnull_20057.html.

Ministry of Education, et al. (2014, September 3). Establishment of the principal teacher exchange rotation system. Retrieved from http://www.moe.gov.cn/jyb_xwfb/ S271/201409/t20140903_174482.html.

Ministry of Education, et al. (2012, January 9). Announcement on arranging rural migrant workers' children to attend examination for entering post-compulsory education in the host city. Retrieved from http://www.gov.cn/zwgk/2012-08/31/content _2214566.htm.

Ministry of Education \& the State Council. (2018, February 27). The poverty relief office of the state council of the ministry of education issued a notice on the implementation plan for education and poverty alleviation in poverty-stricken areas (2018-2020). Retrieved from http://www.cpad.gov.cn/art/2018/2/27/art_46_79213.html.

The Communist Party of China Central Committee \& the State Council. (2014, December 1). Guojia xinxing chengzhenhua guihua (2014-2020) [Planning of new urbanization in China (2014-2020)]. Retrieved from http://www.gov.cn/zhengce/2014-03/16/ content_2640075.htm.

Wei, Y., \& Gong, Y. (2019). Understanding Chinese rural-to-urban migrant children's education predicament: A dual system perspective. International Journal of Educational Development, 69(1), 39-47. 